\title{
Postoperative outcome of Crohn's disease in 30 children
}

M Besnard, O Jaby, J F Mougenot, L Ferkdadji, A Debrun, C Faure, P Delagausie, M Peuchmaur, Y Aigrain, J Navarro, J P Cézard

\begin{abstract}
Background-Thirty children operated on for Crohn's disease (CD) were reviewed (1975-1994). The aim of the study was to assess their postoperative outcome. Patients-19 boys and 11 girls, aged 15.3 (2) years (range 11.3-20) at surgery were studied.

Results-Surgical indications were acute complications of $\mathrm{CD}$ and chronic intestinal illness. Six months after surgery, 11 of 12 patients had been weaned off steroids, and 22 of 23 patients were weaned off nutritional support; 17 patients without recurrrence had a mean (SD) weight gain of 2.1 (8) $\mathrm{kg}$ and a height gain of 3.36 (3) cm. During 3.1 (2.7) years follow up, 12 patients $(40 \%)$ had a recurrence of the disease after 19.4 (14) months (means (SD)): supra-anastomotic recurrence (six), severe perianal disease (two), and chronic illness (four). Six of 14 patients who were treated with mesalazine (13) or azathioprine (one) had recurrences. The postoperative recurrence rate was $50 \%$ at two years.

Conclusion-Surgical treatment modifies the immediate outcome of severe or complicated CD, but does not prevent recurrence, despite localised resection or prophylactic postoperative treatment. Extension of the disease before surgery seems to be a major risk factor for postoperative recurrence in children.

(Gut 1998;43:634-638)
\end{abstract}

Keywords: Crohn's disease; surgery; children

M Besnard

J F Mougenot

C Faure

J Navarro

J P Cézard

Paediatric Surgery

Department

O Jaby

P Delagausie

Y Aigrain

Pathology Department

L Ferkdadji

M Peuchmaur

Biostatistics

A Debru

Correspondence to:

Dr Marianne Besnard, PO

Box 545, Papeete, 98713

Tahiti, French Polynesia.

Accepted for publication 16 April 1998 localised ileocaecal involvement. We report a retrospective study of 30 children operated on for $\mathrm{CD}$, focusing on their postoperative outcome.
Patients and methods

From 1975 to 1994,119 children and adolescents were treated for CD in our department. Local surgery was performed for perianal disease in 29 cases (abscesses and fistula drainage, dilation of stenosis). Diagnostic laparotomies $(n=2)$ were excluded from the study as the diagnosis of CD was not known. So, 36 patients $(30 \%)$ with CD underwent major surgery such as curative resection and/or strictureplasties in the Paediatric Surgery Department. The data for six of the patients were not available for analysis. The remaining 30 patients comprised 19 boys and 11 girls (sex ratio 1.7); the mean (SD) age at $\mathrm{CD}$ diagnosis was 12.2 (2) years (range 7.5-16.5) and the mean (SD) age at surgery was 15.3 (2) years (range 11.3-20). The mean number of flare ups before surgery was 2 (0.9) (range 0-4). The severity of CD before surgery was estimated by a paediatric CD activity index (>30 indicates severe disease). The sites of CD lesions were determined by radiology, upper gastrointestinal tract endoscopy, and colonoscopy: lesions were described according to their site, characteristics, and severity (superficial or deep ulcers, strictures), and biopsies were always performed. Patients were divided into two groups according to disease location before surgery: group 1 , localised disease $(n=6)$, with preoperative recurrence at the same site, with no other site in the upper gastrointestinal tract or perianal area; group 2, multifocal disease (n $=24$ ), with involvement of another site other than the one operated on.

The main sites of lesion in CD are ileal $(\mathrm{n}=$ 6 ) and ileocaecal $(n=7)$, with only six cases (three ileal, three ileocaecal) actually being unifocal (group 1) and multifocal ileocolonic ( $n=17$ ) disease. In group 2, 12 children had perianal lesions and 17 had inflammation of the stomach and duodenum, with specific granulomas in seven cases. Seven of the 30 children had both upper gastrointestinal and anal sites of involvement. Immediately before surgery, 18 children were treated with total parenteral nutrition and five with continuous enteral nutrition. Twelve were receiving steroids and four immunosuppressive drugs; 17 were receiving salicylates. Postoperative follow up took into account recurrences (new sites in a patient who underwent complete removal of macroscopic CD lesions ${ }^{9}$ ) and relapses (reappearance of CD activity on residual lesions). We defined postoperative recurrences as the reappearance of clinical and biological signs after surgery (paediatric CD activity index $>30$ ), as postoperative endoscopy was only 
Table 1 Clinical and paraclinical characteristics of children operated on for Crohn's disease

\begin{tabular}{|c|c|c|}
\hline Characteristic & $\begin{array}{l}\text { Postoperative } \\
\text { recurrence }(n=12)\end{array}$ & $\begin{array}{l}\text { No postoperative } \\
\text { recurrence }(n=18)\end{array}$ \\
\hline Age (years) at diagnosis of Crohn's disease & $11.8(2)$ & $12.4(1.8)$ \\
\hline Age (years) at surgery & 15.3 & 15.4 \\
\hline Duration (years) of preoperative Crohn's disease & 3.5 & 3.2 \\
\hline \multicolumn{3}{|l|}{ Surgical indication } \\
\hline Perforation & 2 & 1 \\
\hline Severe perianal disease & 0 & 1 \\
\hline Abscess & 1 & 0 \\
\hline Ileocolonic fistula & 2 & 1 \\
\hline Intractable pancolitis & 3 & 2 \\
\hline Persistent stricture & 9 & 15 \\
\hline Ileal & 6 & 14 \\
\hline Colonic & 3 & 1 \\
\hline \multicolumn{3}{|l|}{ Sites of Crohn's disease } \\
\hline Ileal & 2 & 4 \\
\hline Ileocaecal & 2 & 5 \\
\hline Ileocolonic & 8 & 9 \\
\hline \multicolumn{3}{|l|}{ Extent of Crohn's disease } \\
\hline Perianal & 6 & 6 \\
\hline Upper intestine & 12 & 5 \\
\hline Faecal diversion & 3 & 4 \\
\hline Ileostomy & 2 & 3 \\
\hline Sigmoidostomy & 3 & 2 \\
\hline Duration (months) of enterostomy & 2.8 & 1.3 \\
\hline Immediate postoperative mobidity & 2 & 0 \\
\hline Long term surgical complication & 1 & 1 \\
\hline Weaning off nutritional assistance (months) & 5.9 & 3.7 \\
\hline Weaning off steroids (months) & 4.5 & 1.8 \\
\hline Postoperative preventive treatment & 6 & 8 \\
\hline Duration (years) of follow up & 8.3 & 5 \\
\hline
\end{tabular}

carried out if major symptoms occurred. The histopathological limits of the resected specimens were reviewed by the same pathologist to assess their influence on the postoperative outcome. After surgery, the patients were divided into two groups: those with recurrences $(\mathrm{n}=$ 12 ) and those with no recurrences $(n=18)$.

We analysed risk factors for postoperative recurrence, comprising sites, extension, severity, number of relapses, presence of perianal disease, aspect of the surgical resection wedge, and preoperative treatment. Statistical analysis was based on Fisher's exact test (significant at $\mathrm{p}<0.05)$. Table 1 details all the clinical and paraclinical characteristics of patients with and without postoperative recurrence.

\section{Results}

SURGICAL INDICATIONS

Six patients had severe intractable ileopancolitis. In 24 patients $(75 \%)$, the surgical indication was a persistent stricture of the terminal ileum. Of these, four had initial extension of $\mathrm{CD}$ to the colon, but medical treatment limited the disease to the ileum.

SURGICAL MANAGEMENT

Ileocolonic resection was the main procedure. The mean (SD) length of resection was 28 (24) $\mathrm{cm}$ of ileum and 21.7 (31) $\mathrm{cm}$ of colon. Seven patients had faecal diversion for an average of 9.3 months. Strictureplasties were performed in two cases, both combined with ileocolonic resection. Two total coloproctectomies were performed, one of which with ileoanal pouch, was carried out for a mistaken initial diagnosis of ulcerative colitis.

POSTOPERATIVE OUTCOME

Postoperative morbidity was low, with two immediate complications (suture leakage and pelvic haemorrhage) and two late complica-

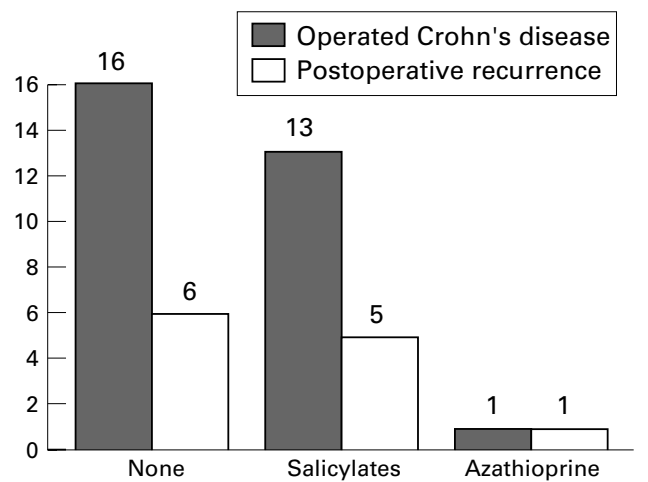

Figure 1 Postoperative treatment and recurrence of Crohn's disease.

tions (diarrhoea with soiling and anal stricture). The mean (SD) postoperative follow up was 3.1 (2.7) years (range 0.3-9). Six months after surgery the mean weight gain was 2.11 (8) $\mathrm{kg}$ and the mean height gain $3.36(2.8) \mathrm{cm}$ in 17 of the 26 patients who had not relapsed at that time. In 16 of the 17 patients growth was normalised, and one patient had a partial growth correction from $-3 \mathrm{SD}$ to $-2 \mathrm{SD}$. Steroid administration was tapered off in 11 of 12 cases, and 22 of 23 patients had been weaned off nutritional assistance six months after surgery.

\section{POSTOPERATIVE RECURRENCE}

Twelve $(40 \%)$ patients had postoperative CD recurrences (mean 19 (14) months). Six of them had undergone right ileocolonic resection, one a coloproctectomy, four subtotal colectomies with ileorectal anastomosis, and one an ileal resection. Only four patients (33\%) had ileal or ileocaecal disease and eight had ileocolonic disease. Among the latter, the mean time to recurrrence was one year. The two cases of localised ileitis recurrence were found 3.3 and 4 years after surgery. Seven patients had an upper gastrointestinal extension and one had specific lesions. Of eight patients investigated, six had a recurrence at the pre-anastomotic site: the ileocolonic anastomosis was ulcerated in three patients and strictured in the other three. Two had severe progressive perianal disease (ulcerated stricture and rectovaginal fistula). Three patients were operated on again (two had permanent ileostomies and one ileocolonic resection).

The two year recurrence-free rate was $50 \%$, with a mean (SD) postoperative follow up of patients with recurrence of 4.75 (3) years (range 0.3-9). Prophylactic postoperative treatment consisted of salicylates in 13 cases and azathioprine in one: six of these patients (43\%) had recurrences, including the patient receiving azathioprine (fig 1 ).

RISK FACTORS FOR POSTOPERATIVE

RECURRENCES: HISTOLOGICAL REVIEW AND STATISTICAL ANALYSIS

Biopsy specimens from 22 patients were reviewed to determine the histological nature of the margins. Ten of the 12 patients who had recurrence after surgery were reviewed: five had pathological margins, with granulomas on 
the ileal side (three) and inflammation on the colonic side (two), whereas the five other children had normal resection margins. Three patients had mild anomalies of CD (inflammation, superficial ulcers, granuloma) and were doing well two to six years after surgery, as did the other nine patients with normal margins and no clinical recurrences.

There was no statistically significant difference between the patients with and without postoperative recurrence with regard to age at diagnosis and at surgery, preoperative duration and activity of CD, ileocolonic sites, and extension of CD. All patients who had recurrences had upper gastrointestinal $(\mathrm{n}=7)$ or perianal $(n=7)$ extension at least once before surgery, whereas four patients with unifocal CD had no recurrences. Thus $50 \%$ of right sided ileocolonic resections recurred, but all these patients had other sites of involvement before surgery. There was also no difference between the two groups with respect to preoperative nutritional and medical support, surgical indications and procedures, and preventive postoperative treatment with mesalazine or azathioprine.

\section{Discussion}

There is no ideal treatment for CD. Surgery is the last resort, after unsuccessful medical therapy or because of acute complications (stricture, perforation, abscess, fistula, severe perianal disease). The adolescent patient's view of this chronic illness, with growth and pubertal failure, prolonged medical treatment, and the inconvenience of nutritional support must also be taken into account in therapeutic decisions.

Management of our paediatric population with $\mathrm{CD}$ after surgery shows that the sex ratio and mean age at diagnosis were similar to those of other children treated for CD in our institution, and in the literature. ${ }^{310}$ Growth failure was frequent in our patients, but was never the sole indication for surgery, unlike in other series. $^{10}$ The distribution of sites of CD involvement was similar to that described in the literature, ${ }^{3}$ with predominant right sided ileocolonic disease (more than $60 \%$ of cases in childhood). Surgical procedures were the same, with attempts to be as cost-effective as possible and the use of strictureplasties when possible. ${ }^{11}$ The results of total ileocoloproctectomy with an ileoanal pouch for CD are very controversial. ${ }^{12}$ It was performed in our series on a patient initially thought to have fulminant ulcerative colitis, and restoration had to be discontinued when CD was diagnosed. The other patient with severe pancolitis needed a coloproctectomy with a definitive stoma. Subtotal colectomy with ileorectal anastomosis was performed in five of our cases; it yields favourable functional results in adults, but requires a healthy rectum. ${ }^{13}$ Surgery had a favourable effect on weight and height at six months in our series, as in others $5^{51014}$; the growth benefit seems to be more frequent in disease localised to the small bowel. ${ }^{516}$ However, some conditions ${ }^{717}$ need to be met for surgery to achieve successful effects on growth: onset of
CD before puberty, retarded bone development of two years, and complete excision of $\mathrm{CD}$ lesions, given that the growth gain may be compromised by the first postoperative recurrence. The most common complication of surgery for CD is recurrence, but its frequency is very variable depending on the definition (clinical, radiological, endoscopic, surgical) and on the duration of follow up. Actuarial survival tables are far more accurate than crude rates of recurrence. In our series, the rate of recurrence ( $50 \%$ at two years) was higher than in the paediatric literature $(50 \%$ at five years)..$^{3-5} 101617$ The risk for a second operation seems particularly high for some authors, ${ }^{8} 60 \%$ of these patients requiring a second operation within five years, whereas we had a $10 \%$ reoperation rate at five years. Furthermore $15 \%$ of the patients of the same series needed a permanent stoma, ${ }^{8}$ whereas only two of our patients were definitively diverted.

Risk factors for postoperative recurrence in adult and paediatric populations have been essentially studied in the adult population. A young age has been reported to adversely affect postoperative outcome, especially because of the early timing of surgery and the long postoperative course. ${ }^{1618}$ However, it is no longer considered a major risk factor in many actuarial studies. ${ }^{45-21}$ The site and extension of the disease seem to be important prognostic factors, but are controversial ${ }^{15} 10141822$ in both adults and children. The surgical indications can influence the risk of recurrence, such as failure of medical treatment, ${ }^{5}$ perforating disease, ${ }^{9}$ and severe preoperative endoscopic lesions. $^{21}{ }^{23}$ The length of the lesion can also be predictive of recurrence: a pathological specimen longer than $90 \mathrm{~cm}$ of small intestine can carry a high risk. ${ }^{24}$ The site of the disease has a variable influence on the risk of recurrence, ${ }^{19} 24$ which seems to be higher in ileal and ileocolonic disease $(50 \%)$ than in isolated colonic disease $(25 \%)$. However, most studies have shown that limited resection of a localised $\mathrm{CD}$ lesion has an excellent prognosis, ${ }^{4}$ whereas extensive ileocolonic disease has a poor outcome especially in children. ${ }^{3-5}$ Children with extensive ileocolonic disease have earlier and more frequent recurrences $(50 \%$ at one year), with a higher risk of repeat surgery than those with unifocal ileal or ileocaecal or colonic lesions (50\% at five years). ${ }^{45} 81425-27$ In our series, 33\% (4/13) of localised ileal or ileocaecal lesions recurred, nearly as many as for pancolitis $(47 \%, 8 / 17)$. However, the four ileal or ileocaecal forms that relapsed were in patients who had other preoperative CD lesions, such as upper gastrointestinal or perianal disease. Thus a precise preoperative staging of CD seems to have a major influence on the time and frequency of postoperative recurrence.

Indications for surgery for CD remain the same from initial to subsequent operations, and the time interval between two operations for perforating forms of CD (perforation, fistula, abscess) is half that for non-perforating forms (stricture, haemorrhage). ${ }^{9}$ Ileocolonic disease is more often perforating ( $57 \%$ ) than disease at other sites ( $41 \%$ for ileum, $46 \%$ for colon), and 
internal fistulae have a greater potential for recurrence ${ }^{28}$; these results were not confirmed in paediatric studies, ${ }^{529}$ including our small study. Some authors ${ }^{24}$ do not consider faecal diversion to be an important factor for relapse, but others consider that it protects the neo-ileum from suffering recurrence. ${ }^{119}{ }^{19-33}$ No recurrence was observed during the temporary diversion of our patients, but three of seven patients had recurrences after restoration of continuity.

Histopathological examination of the resection margins in our series showed, in five of 10 cases of recurrent disease, an abnormal histological aspect, with specific granulomas in three cases. Nine of 12 resection limits had a normal aspect in the patients who remained in remission. These data confirm that the presence of granulomas in the surgical specimen, ${ }^{5} 1921$ especially at its limits, ${ }^{19} 2134-36$ does not influence the postoperative risk of recurrence. This is in keeping with recent data on the natural course of postoperative CD, with recurrences usually occurring at the proximal side of the anastomosis. ${ }^{18} 192137$

Follow up of postoperative recurrences by endoscopy initially shows a normal aspect of the mucosa (or pre-aphthoid ulcers ${ }^{38}{ }^{39}$ ) with occasional epithelioid granulomas on biopsy samples, then aphthoid and superficial ulcers over a hyperhaemic mucosa. Their confluence gives rise to large deep ulcers, which may progress towards stricture or perforation of the anastomosis (in 50\% of patients three years after surgery). Postoperative endoscopy, as well as ultrasonographic examination, ${ }^{40}$ can detect subclinical recurrence in $73 \%$ of cases in the first year and $85 \%$ in the third year. ${ }^{41}$ The severity of endoscopic lesions in the first postoperative year has been found to be predictive of symptomatic recurrence $(92 \%$ at three years). ${ }^{29}{ }^{41}$ This suggests that systematic postoperative endoscopy should be performed to determine the type and duration of preventive treatment after surgery.

Multicentre trials of prophylactic postoperative recurrence in adult populations have produced favourable results, ${ }^{42-45}$ notably with mesalazine and sulfasalazine. ${ }^{46}{ }^{47}$ Other therapeutics ${ }^{2}$ include metronidazole during the first three postoperative months, which seems to decrease the severity and time to symptomatic recurrence ${ }^{48}$; azathioprine and budesonide are being assessed in other multicentre studies. In our series, 14 children had postoperative preventive treatment, but $43 \%$ of them relapsed, a rate similar to that in patients without treatment. The small number of our patients could not preclude a difference between paediatric and adult populations with CD.

Many patients ${ }^{514} 25$ feel better after surgery and have functional improvement (disappearance of severe symptoms, ability to eat normally, and reduction of treatment); this wellbeing can be preserved even if relapse occurs $^{10}{ }^{16}{ }^{49}$; many patients state that they would have preferred to have been operated on earlier. ${ }^{50}$ This improvement in quality of life has to be taken into acount when surgery is indicated especially for children. ${ }^{51}$

To conclude, curative resection for paediatric $\mathrm{CD}$ does not prevent recurrence, and the general trend is towards more conservative treatments, such as strictureplasties, in order to prevent the short bowel syndrome. Our study showed no significant risk factor for postoperative recurrence in a small population, but the main published risk factors are extension of the lesion and CD activity. Limited ileal or ileocaecal disease is no longer a guarantee against recurrence, as $50 \%$ of our patients with ileocolic resections suffered a recurrence, especially when other sites of CD were detected before surgery. No prophylactic medical treatment has proven efficacy for postoperative recurrence, but mesalazine, metronidazole, and azathioprine have shown promise in multicentre studies. Postoperative endoscopy should be carried out to determine the type and duration of a preventive treatment. In spite of the frequency and almost inevitable nature of postoperative recurrence, many patients live well with their relapse $\left(75 \%{ }^{10}\right)$. Surgery can attenuate symptoms and lead to weight and height gain, together with a fair quality of life and limited therapeutic assistance.

1 Greenstein AJ, Sachar DB, Pasternack BS. Reoperation and recurrence in Crohn's colitis and ileocolitis: crude and cumulative rates. N Engl f Med 1975;293:685-90.

2 Rutgeerts PJ. Prevention of early recurrence of Crohn's disease after ileal resection with ileocolonic anastomosis. Eur $\mathcal{F}$ Gastroenterol Hepatol 1994;6:113-16.

3 Gryboski JD, Spiro HM. Prognosis in children with Crohn's Gryboski JD, Spiro HM. Prognosis in child

4 Puntis J, Neish AS, Allan RN. Long-term prognosis of Crohn's disease with onset in childhood and adolescence. Gut 1984;25:329-36.

5 Griffiths AM, Wesson DE, Shandling B, et al. Factors influencing postoperative recurrence of Crohn 's disease in childhood. Gut 1991;52:491-5.

6 Maclain BI, Davidson PM, Beasley SW, et al. Crohn's disease: the Melbourne experience. Pediatric Surgery International 1992;7:165-70.

7 Evans CM, Kirk JMW, Savage MO, et al. Growth after gut resection for Crohn's disease. Arch Dis Child 1991;66:370.

8 Sedgwick DM, Barton JR, Hamer-Hodges DW, et al. Population-based study of surgery in juvenile onset Crohn's disease. Br $\mathcal{F}$ Surg 1991;78:171-5.

9 Lee ECG, Papaioannou N. Recurrences following surgery in Crohn's disease. Clin Gastroenterol 1980;9:419-38.

10 Castile RG, Telander RL, Cooney DR, et al. Crohn's disease in children: assessment of the progression of disease, in children: assessment of the progression of disea

11 Oliva L, Wyllie R, Alexander F, et al. The results of strictureplasty in pediatric patients with multifocal Crohn's disease. F Pediatr Gastroenterol Nutr 1994;18:306-10.

12 Telander RL, Spencer M, Perrault J, et al. Long-term follow-up of the ileoanal anastomosis in children and young adults. Surgery 1990;108:717-25.

13 Longo WE, Oakley JR, Lavery IC, et al. Outcome of ileorectal anastomosis for Crohn's colitis. Dis Colon Rectum 1992; 35:1066-71.

14 Farmer RG, Whelan G, Fazio VW. Long-term follow-up of patients with Crohn's disease. Gastroenterology 1985;88: 1818-25.

15 Alperstein G, Daum F, Fisher SE, et al. Linear growth following surgery in children and adolescents with Crohn's disease: relationship to pubertal status. ₹ Pediatr Surg 1985; 20:129-33.

16 Wesson DE, Shandling B. Results of bowel resection for Crohn's disease in the young. F Pediatr Surg 1981;16:44952.

17 Homer DR, Grand RJ, Colodny AH. Growth, course and prognosis after surgery for Crohn's disease in children and adolescents. Pediatrics 1977;59:717-25.

18 Williams JG, Wong WD, Rothenberger DA, et al. Recurrence of Crohn's disease after resection. Br f Surg 1991;78: $10-19$.

19 Sachar DB, Wolfson DM, Greenstein AJ, et al. Risk factors for postoperative recurrence of Crohn's disease. Gastroenterology 1983;85:917-21.

20 Higgens C, Allan RM. Crohn's disease of the distal ileum. Gut 1980;21:933-40.

21 Rutgeerts JP, Geboes K, Vantrappen G, et al. Natural history of recurrent Crohn's disease at the ileocolonic anastomosis after curative surgery. Gut 1984;25:665-72. 
22 Michelassi F, Balestracci T, Chapell R, et al. Primary and recurrent Crohn's disease. Experience with 1379 patients. recurrent Crohn's disease.

23 Dedombal FT, Burton I, Goligher JC. Recurrence of Crohn's disease after primary excisional surgery. Gut 1971; 12:519-27.

24 Hellberg R, Hulten L, Rosengren C, et al. The recurrence rate after primary excisional surgery for Crohn's disease. Acta Chirurgica Scandinavica 1980;146:435-43.

25 Coran AG, Klein MD, Sarahan TM. The surgical management of terminal ileal and right colon Crohn's disease in children. F Pediatr Surg 1983;18:592.

26 Davies G, Evans CM, Walker-Smith JA. Surgery for Crohn's disease in childhood: influence of site of disease and operative procedures on outcome. Br F Surg 1990;77:891.

27 Lock MR, Fazio VW, Farmer RG, et al. Proximal recurrence and the fate of the rectum following excisionnal surgery for Crohn's disease of the large bowel. Ann Surg 1981;194: 754-60.

28 Greenstein AJ, Lachman P, Sachar DB, et al. Perforating and non-perforating indications for repeated operations in
Crohn's disease: evidence for two clinical forms. Gut 1988 ; Crohn's dis

29 Olaison G, Smedh K, Sjodahl R. Natural course of Crohn's disease after ileocolic resection: endoscopically visualised ileal ulcers preceding symptoms. Gut 1992;33:331-5.

30 Winslet M, Andrews H, Allan R, et al. Fecal diversion in the management of Crohn's disease of the colon. Dis Colon Rectum 1993;36:757-62

31 Goligher JC. The long-term results of excisional surgery for primary and recurrent Crohn's disease of the large intestine. Dis Colon Rectum 1985;28:51-5.

32 Rutgeerts P, Geboes K, Peeters M, et al. Effect of fecal stream diversion on recurrence of Crohn 's disease in the neoterminal ileum. Lancet 1991;338:771-4.

33 Cameron JL, Hamilton SR, Coleman J, et al. Patterns of ilea recurrence in Crohn's disease. A prospective randomized study. Ann Surg 1992;215:546-52.

34 Hamilton SR, Reese J, Pennington L, et al. The role of resection margin frozen section in the surgical manageresection margin frozen section in the surgical management

35 Hulten L. Surgical management and strategy in classical Crohn's disease. Int Surg 1992;77:2-8.

36 Wolff BG, Beart RWJr, Frydenberg HB, et al. The mportance of disease-free margins in resections for Crohn's disease. Dis Col Rectum 1983;26:239-43.

37 Fasth S, Hellberg R, Hulten L. Site of recurrence, extent of ileal disease and magnitude of resection in primary and recurrent Crohn's disease. Acta Chirurgica Scandinavica 1981;147:569-76.
38 Sankey EA, Dhillon AP, Anthony A, et al. Early mucosal changes in Crohn's disease. Gut 1993;34:375-81.

39 Rutgeerts PJ, Geboes K. Inflammatory bowel diseaseCrohn's disease and pre-aphthoid lesions. Lancet 1993;341 $1443-4$

40 Dicandio G, Mosca F, Campatelli A. Sonographic detection of postsurgical recurrence of Crohn's disease. $A \mathscr{f R} A m \mathcal{F}$ Roentgenol 1986;146:523-6.

41 Rutgeerts P, Geboes K, Vantrappen G, et al. Predictability of the postoperative course of Crohn's disease. Gastroenterology 1990;99:956-63.

42 Caprilli R, Andreoli A, Capurso L, et al. Oral 5ASA (Asacol) in the prevention of Crohn's disease postoperative recurrence. Aliment Pharmacol Ther 1994;8:35-43.

43 Brignola C, Cottone M, Pera A, et al. Mesalamine in the prevention of endoscopic recurrence after intestinal resection for Crohn's disease. Gastroenterology 1995;108:345-9.

44 Fiasse R, Fontaine F, Vanheuverzwyn R. Prevention of Crohn's disease recurrences after intestinal resection with Eudragit-L-coated 5ASA? Preliminary results of a one-year double-blind placebo controlled study. [Abstract] Gastroenterology 1991;100:A208.

45 Florent CH, Cortot A, Quandale P. Placebo-controlled trial of Claversal in the prevention of early endoscopic relapse after curative resection for Crohn's disease. [Abstract] Gastroenterology 1992;102:A623.

46 Wenckert A, Kristensen M, Eklund AE, et al. The long-term prophylactic effect of salazosulfapyridine (salazopyrin) in primarily resected patients with Crohn's disease: a controled double-blind trial. Scand f Gastroenterol 1978;13:161-

47 Ewe K, Herfarth C, Malchow $\mathrm{H}$, et al. Postoperative recurrence of Crohn's disease in relation to radicality of operation and sulfalazine prophylaxis: a multicenter trial. Digestion 1989;42:224-32.

48 Rutgeerts JP, Hiele M, Geboes K, et al. Controlled trial of metronidazole treatment for prevention of Crohn's recurrence after ileal resection. Gastroenterology 1995;108:161721.

49 Meyers S, Walfish JS, Sachar DB, et al. Quality of life after surgery for Crohn's disease: a psychosocial survey. Gastroenterology 1980;78:1-6.

50 Scot NA, Hughes LE. Timing of ileocolonic resection for symptomatic Crohn's disease: the patient's view. Gut 1994; 35:656-7.

51 Rabbett H, Elbadri A, Thwaites R, et al. Quality of life in children with Crohn's disease. F Pediatr Gastroenterol Nutr 1996;23:528-33. 